\title{
Towards Green Remediation: Metal Phytoextraction and Growth Analysis of Sorghum bicolor under Different Agronomic Management
}

\author{
Guido Fellet, Luca Marchiol
}

Dipartimento di Scienze Agrarie e Ambientali, Università degli Studi di Udine, Udine, Italy.

Email: \{guido.fellet, marchiol\}@uniud.it

Received February 25 $5^{\text {th }}, 2011$; revised March $15^{\text {th }}, 2011$; accepted March $25^{\text {th }}, 2011$.

\begin{abstract}
The role agronomy plays in the management of phytotechnologies is a significant example of the answers that the agrosciences can offer to the issues of society in the field of Green Remediation. This paper reports a study designed to test how the principles of classical plant growth analysis can be used in the field of phytoremediation. In the framework of a phytoremediation field trial set up in Torviscosa (Udine, Italy), Sorghum bicolor was grown receiving mineral fertilization, organic amendment, or neither as control. Crop growth was examined following classical functional growth analysis. Leaf area index (LAI), relative growth-rate (RGR) and shoot to weight ratio (SWR) showed how plants behaved in response to the treatments. Sorghum bicolor showed a poor potential for phytoremediation under our experimental conditions. However, some parameters of classical crop growth analysis resulted potentially useful also in the field of phytoremediation.
\end{abstract}

Keywords: Green Remediation, Heavy Metals, Phytoextraction, Field Experiment

\section{Introduction}

The heavy metals soil contamination is of great concern due to its potential impact on human and animal health. The traditional soil clean-up treatments take place by means of technologies based on a physicochemical approach (e.g. solidifications and stabilizations, soil washing, electrokinetics, redox reactions). Such technologies are costly, have substantial side effects and are power consuming [1].

The Green Remediation (GR) is the practice of considering all environmental effects of a clean-up process during each phase, and incorporating strategies to maximize the net environmental benefit of the clean-up. The GR reduces the demand placed on the environment during clean up actions, otherwise known as the "footprint" of remediation, and avoids the potential for collateral environmental damage [2].

The term "phytotechnologies" includes a variety of in situ gentle techniques of environmental remediation. Phytotechnologies can be applied to inorganic contaminants, such as heavy metals, metalloids, radioactive materials, and salts [3] and potentially offer efficient and environmentally friendly solutions for the clean-up of contaminated soils contributing to a sustainable land use management [4].

Phytoextraction is one of the different options offered by the phytotechnologies that typically is used to address metals, metalloids and radionuclides [3]. Phytoextraction involves the use of plants to remove contaminants from the soil. The aerial biomass, which accumulated heavy metals can be removed and disposed or burnt to recover the metals. Biomass may require periodic harvesting and proper disposal to avoid metal release when the plants die or drop their leaves [3].

The amount of pollutants removed by the plants from the contaminated soil is calculated by multiplying the harvestable crop biomass and the concentration of the pollutants within the biomass. The phytoextraction efficiency for a given species is determined by 1) The plant biomass production and 2) The metal bioaccumulation factor (shoots to soil metal concentration ratio) [5].

Therefore, phytoextraction is essentially an agronomic approach and its success depends ultimately on the agronomic practices (including the proper plant/crop choice) that should be optimized in order to enhance the efficiency of the soil clean-up process to the site specific 
conditions.

The fundamental role of agronomy in the management of phytoremediation systems is a significant example about the role that agrosciences can offer to answer to the issues of society in the perspective of GR [6].

Despite the intensive research in the last decade, another widening gap between science and practicality lays on the fact that very few field trials have been realized. So far, unrealistic field scale extrapolations from experimental data from lab and greenhouse trials have raised doubts about the feasibility of metal phytoextraction [7].

An up-to-date inventory of the field trials performed in Europe in the years 2000-2008 is reported by Mench et al. [8]. Regarding Italy, the field experiment of Torviscosa is cited and-so far-it is the only phytoremediation experiment performed at field scale within an industrial site [9]. As this trial was managed by our group, the present study reports a study that shows 1) How the principles of plant growth analysis [10] can be used in the field of phytoremediation, and 2) Reports the uptake and removal of elements recorded growing Sorghum bicolor in a multi-metal contaminated soil.

\section{Materials and Methods}

The experiment at Torviscosa, NE Italy $\left(45^{\circ} 49^{\prime} \mathrm{N}, 13^{\circ} 16^{\prime}\right.$ $\mathrm{E}, 14 \mathrm{~m}$ above sea level, mean annual temperature $13.5^{\circ} \mathrm{C}$, average annual rainfall $1200 \mathrm{~mm}$ ) was organized in a randomized block design with two factors, species and treatment, and three replications [9]. The substrate of the experimental site is polluted by several heavy metals and As; currently, this site and the surroundings are included in the national priority list of polluted sites. In this paper, the term soil will be referred to the heavy metals rich substrate from Torviscosa even though the substrate is not properly a soil.

The plant growth analysis and the results reported in this paper are referred to Sorghum bicolor. The experiment of Torviscosa basically dealt with different fertilization strategies. The plants were subjected to three different agronomic treatments: control (CT, the local metal enriched substrate), mineral fertilization (MF) and organic amendment (OA). More detailed information is provided by Marchiol et al. [9].

Growth stages during the crop cycle were recorded following Vanderlip [11]. Plant sampling started 40 days after sowing. Plants were taken for analysis at 42 days, 56 days, 70 days, 84 days, 98 days and 112 days after sowing. Six plants were collected from an area of $0.4 \mathrm{~m}^{2}$ from each plot. The plants were harvested with a shovel. All plant fractions (roots, leaves, shoots and heads) were washed carefully with demineralised water.

\subsection{Chemical Analysis}

Soil samples, collected to determine the main soil parameters and the metal concentrations, were dried at room temperature for two days, sieved to $<2 \mathrm{~mm}$ and their particle size measured by the Bouyoucos hydrometer method [12]. The $\mathrm{pH}$ of each sample was measured in a soil/water slurry at a $1 / 2.5$ ratio.

The plant specimens were divided into the following fractions: root apparatus and aboveground biomass (further on divided into roots and shoots for the plant growth analysis indexes). Plant fractions were rinsed with abundant tap water to remove dust or adhering particles and carefully washed with deionized water.

The soil and plant samples were oven-dried at $105^{\circ} \mathrm{C}$ for $24 \mathrm{~h}$ and acid-digested in a microwave oven (CEM, MARSXpress) according to the USEPA 3051 and 3052 method, respectively $[13,14]$. After mineralization, both the soil and plant extracts were filtered $(0.45 \mu \mathrm{m}$ PTFE), diluted and analysed. Total $\mathrm{Cd}, \mathrm{Cr}, \mathrm{Cu}, \mathrm{Fe}, \mathrm{Pb}$ and $\mathrm{Zn}$ contents in the extracts were determined by means of an ICP-OES (Varian Inc., Vista MPX). The measurement of As was done separately with a continuous-flow vapour generation system that provided improved detection limits for this element (VGA-77, Varian Inc.).

\subsection{Statistical Analysis}

Pearson's correlation coefficient analysis was undertaken to assess the relationship between the crop biomass yield and its concentrations of $\mathrm{As}, \mathrm{Cd}, \mathrm{Co}, \mathrm{Cu}, \mathrm{Pb}$, and $\mathrm{Zn}$, and between elements. The calculated coefficients were tested for significance with Student-Newmann-Keuls' test. Experimental data were subjected to a two-way ANOVA $(p<0.05)$ to examine the effects of the agronomic strategies. Differences between means were determined using Student-Newmann-Keuls range test $(p<$ $0.05)$.

The accuracy of the analytical procedure was checked with standard solutions every 15 samples. Scandium was used as internal standard. For the statistical analysis, in samples where an element was not detected, its concentration was assumed to be one-half of the respective limits of detection [15]. Detection limits were: $3 \mu \mathrm{g} \cdot \mathrm{L}^{-1}$ for As, $1.5 \mu \mathrm{g} \cdot \mathrm{L}^{-1}$ for $\mathrm{Pb}, 0.9 \mu \mathrm{g} \cdot \mathrm{L}^{-1}$ for $\mathrm{Cu}, 0.4 \mu \mathrm{g} \cdot \mathrm{L}^{-1}$ for $\mathrm{Co}$ and $0.2 \mu \mathrm{g} \cdot \mathrm{L}^{-1}$ for $\mathrm{Cd}$ and $\mathrm{Zn}$.

\subsection{Anti Microbial Functions}

The classical approach to the plant growth analysis is based on data collected at the different sampling dates used to define the adaptation of plants to different agronomic management strategies. Leaf area index (LAI), relative growth rate (RGR) and shoot growth rate (SWR) 
were chosen as indicators.

The basic parameters for the plant growth analysis consisted of the green leaf area (A), dry biomass of roots $(\mathrm{R})$, stalks (S), leaves (L) and heads $(\mathrm{H})$, and the total plant biomass $(\mathrm{W}=\mathrm{R}+\mathrm{S}+\mathrm{L}+\mathrm{H})$. The plant total leaf area (LA) was estimated by measuring the green leaf area of all leaves with a leaf area meter (LI-3100, LI-COR, Lincoln, NE). R, S, L and $\mathrm{H}$ were measured after drying the samples for $24 \mathrm{~h}$ at $105^{\circ} \mathrm{C}$ in a forced-air oven.

The following standard growth analysis parameters were calculated as follows [10]:

Leaf area index (LAI)

$$
L_{A} / P \text { [dimensionless] }
$$

Relative growth rate (RGR)

$$
(1 / W)(\mathrm{d} W / \mathrm{d} T)\left[\left(\mathrm{g} \cdot \mathrm{g}^{-1}\right) \mathrm{d}^{-1}\right]
$$

Shoot weight ratio (SWR)

$$
S_{W} / W \text { [dimensionless] }
$$

where $L_{A}$ is the leaf area, $P$ is the ground area covered by the crop, $W$ is the total plant dry mass, $S_{W}$ is the shoot dry mass and $\mathrm{T}$ is time.

The means of the parameters were transformed to natural logarithms to obtain the homogeneity of errors; thereafter, they were subjected to the smooth curve-fitting to describe the relationships of the indices versus time. LAI data were interpolated with a logistic function, while RGR and SWR data were fit with a first-order and a second-order polynomial curve, respectively.

\section{Results}

\subsection{Soil and Plant Biomass Pollutants Content}

The basic soil parameters and the concentration of heavy metals and As are given in Table 1.

The concentrations of $\mathrm{As}, \mathrm{Cd}, \mathrm{Co}, \mathrm{Cu}, \mathrm{Pb}$ and $\mathrm{Zn}$ in the soil of the experimental site are above the recommended permissible values according to Italian legislation (Decree 152/06). The high Fe content of the pyrite cinders explains the concentration (about 9\%) of this micronutrient in the soil (Table 1). The average total Fe content of temperate soils usually varies in the range $1 \%$ $-5 \%[16]$.

Table 2 shows the output of Pearson correlation coefficients $(r)$ analysis between the aboveground biomass yield of Sorghum bicolor and the concentration of a given element in the biomass, and the correlation between elements recorded for each treatment.

Positive and significant relationships between shoot biomass yield and the concentrations of As (MF $p<0.05$; OA $p=0.01)$, Co (MF $p<0.001$; OA $p=0.01), \mathrm{Cu}(\mathrm{MF}$ $p<0.05$; $\mathrm{OA} p=0.01)$ and $\mathrm{Pb}(\mathrm{MF} p<0.001 ; \mathrm{OA} p=$
Table 1. Characterization of the soil $(0-25 \mathrm{~cm})$ collected at the field trial of Torviscosa. For reference the concentration thresholds for As and heavy metals fixed by Italian and EU legislation respectively, are provided.

\begin{tabular}{cccc}
\hline Parameter & Value & Italy $^{\S}$ & $\mathrm{EU}^{\Uparrow}$ \\
\hline Sand (\%) & 69.4 & & \\
Silt (\%) & 25.4 & & \\
Clay (\%) & 5.17 & & \\
pH $\left(\mathrm{H}_{2} \mathrm{O}\right)$ & 7.75 & & \\
$\mathrm{OC}\left(\mathrm{g} \cdot \mathrm{kg}^{-1}\right)$ & 9.10 & & \\
$\mathrm{CEC}\left(\mathrm{cmol}+\mathrm{kg}^{-1}\right)$ & 5.5 & & \\
$\mathrm{E}\left(\mathrm{mS} \cdot \mathrm{cm}^{-1}\right)$ & 2.65 & & \\
$\mathrm{Fe}(\%)$ & 9.02 & & \\
$\mathrm{As}(\mathrm{ppm})$ & $309^{\dagger} \pm 20^{\ddagger}$ & 20 & - \\
$\mathrm{Cd}(\mathrm{ppm})$ & $4.29 \pm 0.29$ & 2 & 3 \\
$\mathrm{Co}(\mathrm{ppm})$ & $50.9 \pm 2.31$ & 20 & - \\
$\mathrm{Cu}(\mathrm{ppm})$ & $1527 \pm 148$ & 120 & 140 \\
$\mathrm{~Pb}(\mathrm{ppm})$ & $233 \pm 18$ & 100 & 300 \\
$\mathrm{Zn}(\mathrm{ppm})$ & $980 \pm 52$ & 150 & 300 \\
\hline
\end{tabular}

${ }^{\dagger} \mathrm{n}=20 ;{ }^{\ddagger}$ Standard error; ${ }^{\S}$ Decree $152 / 06 ;{ }^{\uparrow} 86 / 278 /$ EU Directive.

0.01) were found (Table 2). The concentrations of some elements recorded in the crop biomass were correlated with those of others. In particular, there was a strong positive relationship between As and Co (MF $p<0.001$; OA $p<0.001)$, between As and $\mathrm{Cu}(\mathrm{CT} p<0.001$; MF $p$ $<0.001$; OA $p<0.001$ ) and between As and Pb (MF $p<$ 0.001 ; OA $p<0.001$ ). The concentration of Co had significant positive correlations with the $\mathrm{Cu}$ in $\mathrm{CT}$ and $\mathrm{OA}$ plants (both at $p<0.001$ ), and of $\mathrm{Pb}$ in $\mathrm{CT}, \mathrm{MF}$ and $\mathrm{OA}$ plants at $p<0.001$. Finally, $\mathrm{Cu}$ correlated only with $\mathrm{Pb}$ (CT $p<0.001$; MF $p<0.01$; OA $p<0.001$ ) (Table 2) whereas $\mathrm{Cd}$ did only with $\mathrm{Cu}$ in OA plants $(p<0.05)$ and Zn in respectively CT $(p<0.001)$ and OA $(p<0.05)$ plants (Table 3).

\subsection{Plant Growth Analysis}

The accumulation of the dry matter in the plant fractions during the growth cycle is reported in Figure 1. The different treatments had significant effects on the accumulation of dry matter in the root system (Figure 1a). Since the early stages, the MF plants responded to the readily available nutrients supplied with fertilizers and reached the highest level of dry matter in the roots $\left(4.80 \mathrm{~g} \cdot\right.$ plant $\left.^{-1}\right)$ which is more than twice that of the OA plants $(2.08$ $\left.\mathrm{g} \cdot \mathrm{plant}^{-1}\right)$. The more developed root systems, the greater availability of water and mineral nutrients.

In MF plants, compared to OA plants, a significantly higher accumulation of dry matter in the stalks was observed (11.2 and 6.16 g.plant ${ }^{-1}$, respectively) (Figure 1(b)). 
Table 2. Pearson's correlation coefficient $(r)$ between biomass yield and concentration of elements in the shoots, significant correlations are noted by ${ }^{*} \mathbf{p}<0.05 ;{ }^{* *} \mathbf{p}<0.01$; ${ }^{* *} \mathbf{p}<0.001$.

\begin{tabular}{|c|c|c|c|c|c|c|c|}
\hline $\mathrm{N}=21$ & Treatment & Shoot biomass & $\mathrm{As}_{\text {Shoots }}$ & $\mathrm{Cd}_{\text {Shoots }}$ & Co $_{\text {Shoots }}$ & $\mathrm{Cu}_{\text {Shoots }}$ & $\mathrm{Pb}_{\text {Shoot }}$ \\
\hline \multirow{3}{*}{ As } & CT & -0.354 & & & & & \\
\hline & MF & $0.543^{*}$ & & & & & \\
\hline & $\mathrm{OA}$ & $0.681^{* *}$ & & & & & \\
\hline \multirow{3}{*}{$\mathrm{Cd}_{\text {Shoots }}$} & $\mathrm{CT}$ & -0.296 & 0.372 & & & & \\
\hline & MF & -0.188 & -0.197 & & & & \\
\hline & $\mathrm{OA}$ & -0.012 & 0.162 & & & & \\
\hline \multirow{3}{*}{ Co $_{\text {Shoots }}$} & $\mathrm{CT}$ & -0.149 & 0.459 & 0.278 & & & \\
\hline & MF & $0.757 * * *$ & $0.812^{* * *}$ & -0.208 & & & \\
\hline & OA & $0.827^{* *}$ & $0.842 * * *$ & 0.298 & & & \\
\hline \multirow{3}{*}{$\mathrm{Cu}_{\text {Shoots }}$} & $\mathrm{CT}$ & -0.467 & $0.712 * * *$ & 0.138 & $0.753 * * *$ & & \\
\hline & MF & $0.549 *$ & $0.487 * * *$ & 0.328 & 0.416 & & \\
\hline & $\mathrm{OA}$ & $0.574 * *$ & $0.829 * * *$ & $0.494 *$ & $0.831 * * *$ & & \\
\hline \multirow{3}{*}{$\mathrm{Pb}_{\text {Shoots }}$} & $\mathrm{CT}$ & -0.062 & 0.391 & 0.247 & $0.825 * * *$ & $0.679 * *$ & \\
\hline & MF & $0.790 * * *$ & $0.853 * * *$ & -0.145 & $0.951 * * *$ & $0.536^{*}$ & \\
\hline & $\mathrm{OA}$ & $0.668 * *$ & $0.835 * * *$ & 0.425 & $0.898 * * *$ & $0.961 * * *$ & \\
\hline \multirow{3}{*}{$\mathrm{Zn}_{\text {Shoots }}$} & $\mathrm{CT}$ & -0.058 & 0.461 & $0.927 * * *$ & 0.296 & 0.132 & 0.221 \\
\hline & MF & 0.025 & -0.139 & $0.769 * * *$ & -0.2420 & 0.234 & -0.164 \\
\hline & $\mathrm{OA}$ & -0.251 & -0.158 & $0.551^{*}$ & -0.044 & 0.115 & -0.013 \\
\hline
\end{tabular}

Table 3. Biomass yield and amount of elements removed by CT, MF and OA plants of $S$. bicolor. Data within a column not followed by the same letter indicates significant differences determined by the Student Newman Keuls test.

\begin{tabular}{|c|c|c|c|c|c|c|c|}
\hline \multirow{3}{*}{ Treatment } & \multirow{2}{*}{ Biomass yield } & \multicolumn{6}{|c|}{ Element removal } \\
\hline & & As & $\mathrm{Cd}$ & $\mathrm{Co}$ & $\mathrm{Cu}$ & $\mathrm{Pb}$ & $\mathrm{Zn}$ \\
\hline & $\mathrm{t} \cdot \mathrm{ha}^{-1}$ & $\mathrm{~g} \cdot \mathrm{ha}^{-1}$ & $\mathrm{~g} \cdot \mathrm{ha}^{-1}$ & $\mathrm{~g} \cdot \mathrm{ha}^{-1}$ & $\mathrm{~g} \cdot \mathrm{ha}^{-1}$ & $\mathrm{~g} \cdot \mathrm{ha}^{-1}$ & $\mathrm{~g} \cdot \mathrm{ha}^{-1}$ \\
\hline $\mathrm{CT}$ & $1.54 \mathrm{c}$ & $7.47 \mathrm{a}$ & $0.39 \mathrm{~b}$ & $0.87 \mathrm{~b}$ & $40.1 \mathrm{a}$ & $4.40 \mathrm{a}$ & $147 \mathrm{c}$ \\
\hline $\mathrm{MF}$ & $22.1 \mathrm{a}$ & $110 \mathrm{a}$ & $5.83 \mathrm{a}$ & $16.5 \mathrm{a}$ & $644 \mathrm{a}$ & $78.1 \mathrm{a}$ & $1,223 \mathrm{~b}$ \\
\hline $\mathrm{OA}$ & $16.9 \mathrm{~b}$ & $97.1 \mathrm{a}$ & $4.43 \mathrm{a}$ & $11.5 \mathrm{ab}$ & $681 \mathrm{a}$ & $86.0 \mathrm{a}$ & $1,944 \mathrm{a}$ \\
\hline $\mathrm{ANOVA}^{\dagger}$ & $0.0000^{* * *}$ & $0.0540^{\mathrm{ns}}$ & $0.0094^{* *}$ & $0.0438^{*}$ & $0.0628^{\text {ns }}$ & $0.1192^{\mathrm{ns}}$ & $0.0001^{* * *}$ \\
\hline
\end{tabular}

${ }_{\dagger}^{\dagger} p$ values

As expected, CT plants suffered from the poor quality of the native substrate, storing less than $80 \%$ of dry matter in roots, and less than $17 \%$ in stalks, compared to $\mathrm{MF}$ plants.

The biomass accumulation in the leaves was significantly higher in MF plants than in OA plants (Figure 1(c)). However, this difference was less evident than that reported for roots and stalks.

Finally, we recorded the dynamics of the transfer of dry matter from the vegetative parts of the plants towards the reproductive structures. No difference was observed between MF and OA plants (Figure 1(d)), while CT plants did not succeed in reaching the flowering stage.

Figure 2 reports the growth analysis parameters. The LAI values changed during plant growth from 0.09 to 0.69 in CT plants, from 0.64 to 6.11 in MF plants and from 1.09 to 3.15 in OA plants. Plotting LAI values versus time yielded distinct curves, with lower canopy build-up for CT plants (Figure 2(a)). The growth of $S$. bicolor was affected strongly by the CT conditions; in fact, such plants did not grow beyond the vegetative stage, showing remarkable growth retardation. From growth stage GS2 (fourth leaf), the LAI curve of MF and OA plants diverged, increasing the differences starting from the top of the curve. OA plants grew faster than MF plants, reaching growth stage GS5 (bloom) 14 days before the MF plants did (Figure 2(a)).

The biomass yield of a plant depends on the size of the leaf canopy, the biochemical activity of the leaves, and the canopy persistence. Therefore, the longer vegetative phase of the MF plants contributed to their greater biomass production by delaying the senescence of the canopy (Figure 2(a)).

The RGR functions-which express the increase in plant weight per unit of weight and time-decreased linearly over the sampling period for all three treatment groups (Figure 2(b)). However, while the interpolating functions have a similar slope in MF and OA plants $(m=$ -0.047 and -0.044 , respectively), the gradient of the RGR function of CT plants is lower $(m=-0.002)$, indicating a very slow growth rate. Note that RGR, calculated by Equation (2), indicates the instantaneous values 
Roots $\left(\right.$ g plant $\left.^{-1}\right)$

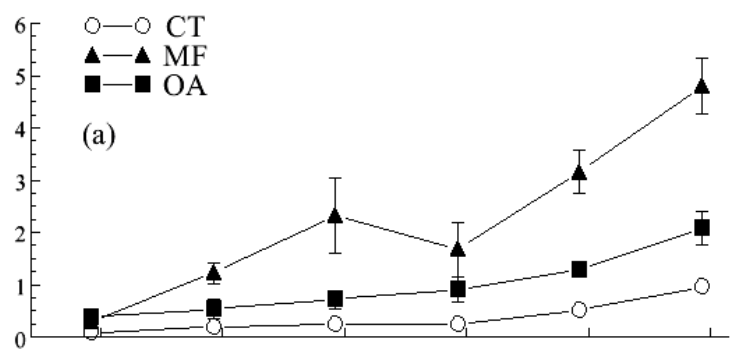

Stalks $\left(\right.$ g plant $\left.^{-1}\right)$

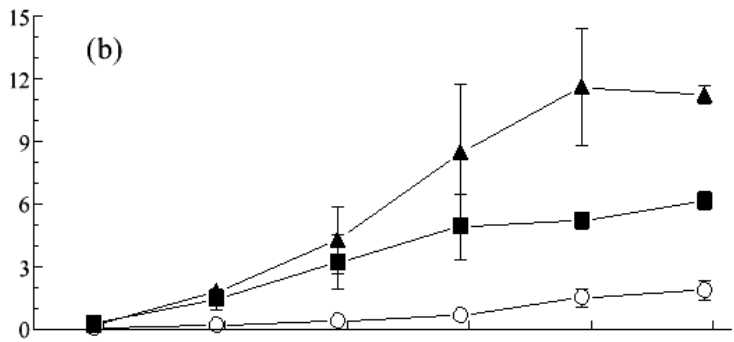

Leaves $\left(\mathrm{g}\right.$ plant $\left.^{-1}\right)$

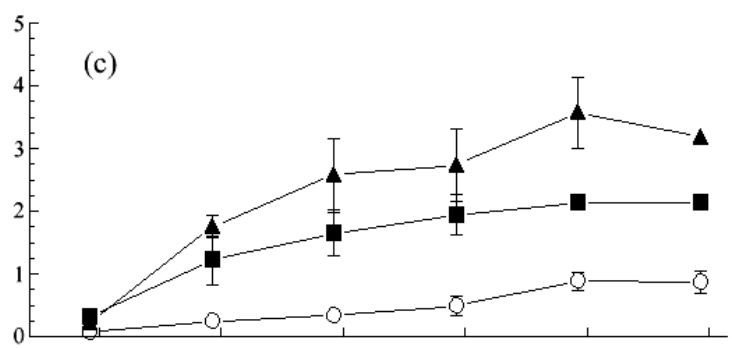

Heads $\left(\right.$ g plant $\left.^{-1}\right)$

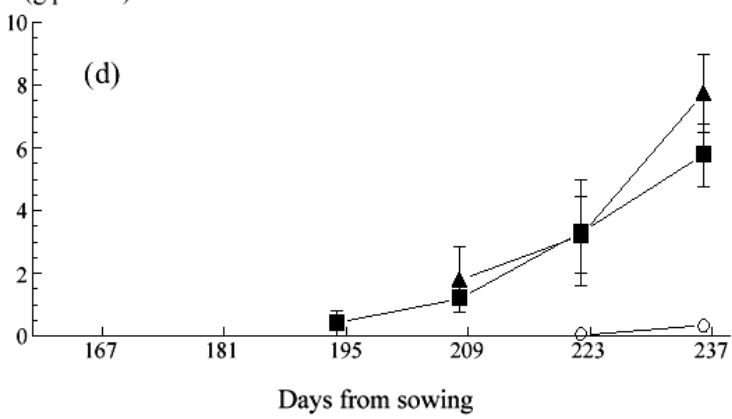

Figure 1. (a) Root, (b) stalks, (c) leaves and (d) heads biomass dry matter of CT, MF and OA plants of Sorghum bicolor. Mean vertical bars represent standard error.

of the parameter during the growth cycle of sorghum; which is why the data are omitted from Figure 2(b).

Figure 2(c) shows the curves for SWR, which is a measure of the shoots biomass as a proportion of the total plant biomass. This is a fundamental parameter in a phytoremediation project, as the agronomic management should provide the maximum biomass yield in order to remove the greatest amount of metals from the soil.
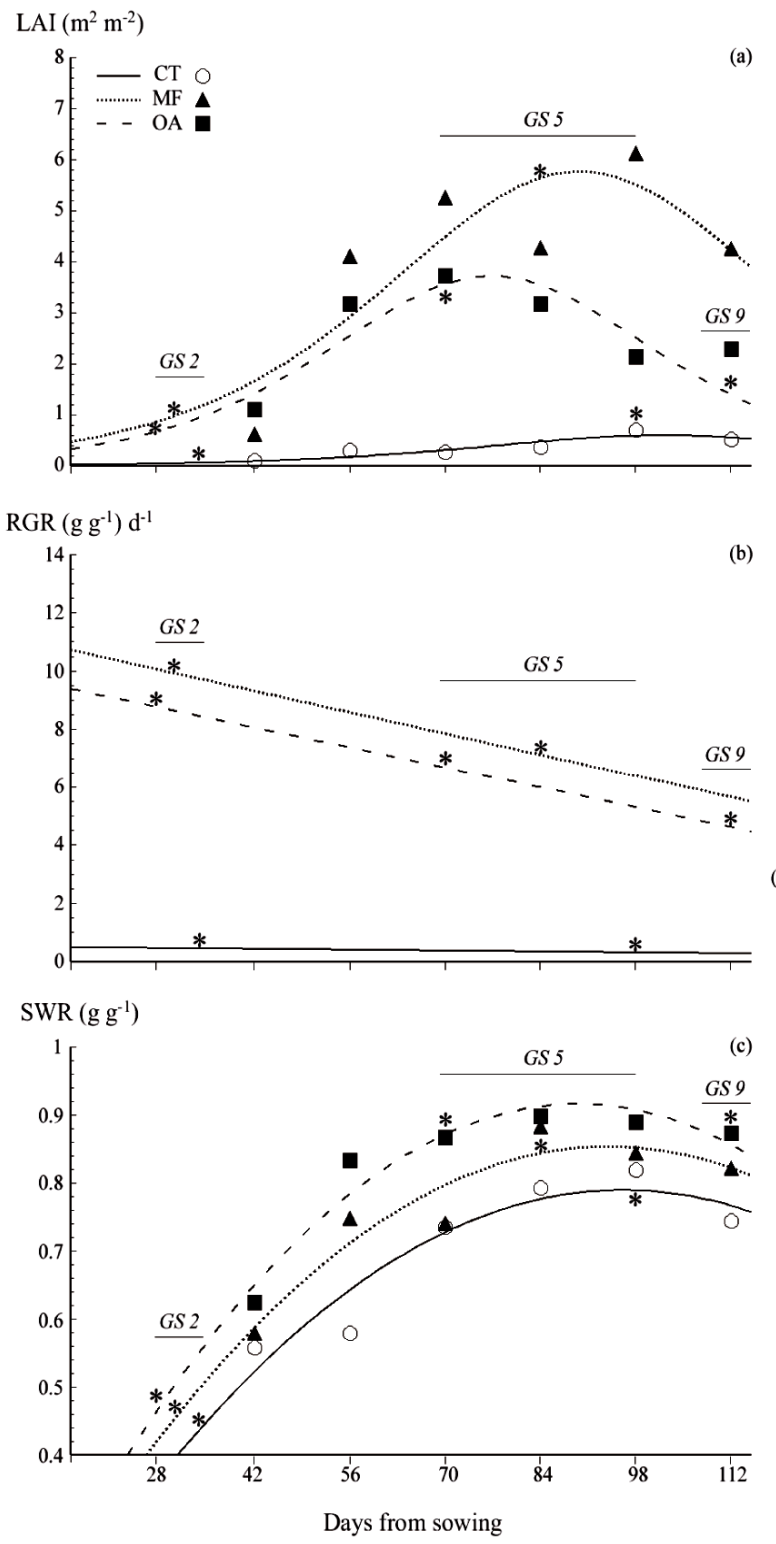

Figure 2. (a) Leaf area index (LAI), (b) Relative growth rate (RGR) and (c) Shoot weight ratio (SWR) as function of time for CT, MF OA plants of $S$. bicolor. Following Vanderlip [11] growth stages GS 2 (4 ${ }^{\text {th }}$ Leaf), GS 5 (Boot) and GS 9 (Physiological maturity) are indicated with “*” and horizontal bars. Data were fitted using logistic (A) and polynomial functions (B,C).

Functions:

$$
\begin{aligned}
& \text { CT: } a=0.59 ; b=227.1 ; c=18.6 ; r^{2}=0.91 \\
& \text { (A) MF: } a=5.76 ; b=214.8 ; c=19.3 ; r^{2}=0.81 \quad y=4 a \frac{e^{\left[-\left(\frac{x-b}{c}\right)\right]}}{\text { OA: } a=3.71 ; b=201.8 ; c=16.4 ; r^{2}=0.88 \quad\left[1+e^{\left[-\left(\frac{x-b}{c}\right)\right]}\right]^{2}} \\
& \text { CT: } y=0.52-0.0018 x ; m=-0.00 \\
& \text { MF: } y=11.34-0.044 ; m=-0.047 \\
& \text { OA: } y=9.96-0.041 x ; m=-0.044 \\
& \text { CT: } y=-3.66+0.040 x-9.11 x^{2} ; r^{2}=0.88 \\
& \text { MF: } y=-3.86+0.043 x-9.83 x^{2} ; r^{2}=0.89 \\
& \text { OA: } y=-4.52+0.051 x-1.18 x^{2} ; r^{2}=0.93
\end{aligned}
$$


$\mathrm{SWR}_{\max }$ indicates the time of highest biomass yield during the crop cycle, providing information to guide the harvest scheduling. Due to growth retardation, the CT plants reached $\mathrm{SWR}_{\max }(0.80)$ at GS5, whereas the MF and OA plants reached GS5 phase in the ascending branch of the SWR curve, and $\mathrm{SWR}_{\max }$ was 0.86 and 0.91, respectively (Figure 2(c)).

\subsection{Removal of elements by crop removal}

The maximum removal of pollutants is achieved by harvesting the plant biomass when the maximum biomass is reached. The values of biomass yield of sorghum obtained in response to the agronomic treatments are showed in Table 3. We recorded an amount of aboveground biomass equivalent to $1.54,22.1$ and $16.9 \mathrm{t}$ of dry matter per hectare for CT, MF and OA plants, respectively.

The amounts of elements removed from the soil were calculated by multiplying the average concentrations of elements in the shoots, reported in Marchiol et al. [9], and the biomass yield (Table 3). Being derived from the plant biomass, this parameter mainly reflects the effects of the different fertilizations observed for the biomass yield. In fact, the input of mineral fertilizers and the organic amendment, having improved the nutritional status of the plants, allowed the removal of greater amounts of elements than in the control treatment. This difference was statistically significant in the case of $\mathrm{Cd}$, Co and $\mathrm{Zn}$ (Table 3). The ANOVA did not indicate a significant effect of the different crop management in the case of As and $\mathrm{Cu}$. Data for MF and OA plants have a certain variability that has hidden the effects of the treatments. Despite this disturbance, the $p$ values obtained from the ANOVA for As $(p=0.054)$ and $\mathrm{Cu}(p=0.062)$ are very close to the standard significance level (0.05) (Table 3).

The biomass of OA plants removed significantly more Zn than the MF plants, $1944 \mathrm{~g} \cdot \mathrm{ha}^{-1}$ vs. $1223 \mathrm{~g} \cdot \mathrm{ha}^{-1}$. These values are about 10 -fold the uptake of $\mathrm{Zn}$ recorded for CT plants.

\section{Discussion}

A great deal of progress has been achieved at experimental level for several approaches offered by phytotechnologies. Several comprehensive reviews by McGrath \& Zhao [5], Pilon-Smits [17], Vangronsveld et al. [18], Wu et al. [1] and Krämer [19], summarized many important aspects of this novel plant-based technology and the achievements of the scientific community. Significant and decisive advances are still expected from research. At this moment we are still far from being able to apply on a large scale the phytotechnologies.

The process of phytoextraction is based substantially on plant-soil interactions where the mass transfer of an inorganic pollutant from the bulk soil to the plant biomass is promoted. This implies that the management of the two elements of the system (plant and soil) should have effects on the efficiency of the process. As phytoremediation is essentially an agronomic approach, its success depends ultimately on standard agronomic practices such as plant species selection, specific soil management practices, fertilization, irrigation and weed and pest control $[20,8]$. Moreover, it is a long-term remediation effort and many cropping cycles to decontaminate metal pollutants to acceptable levels are required. Appropriate and effective schemes of crop rotation should be available.

Here, we present the data collected during the first year of the field study which ran at Torviscosa. We observed the phytoremediation potential of S. bicolor in polycontaminated soil. The plants grew in polluted soil containing six elements above the threshold allowed by the Italian law.

The dearth of descriptions of field experiments on phytoremediation makes it difficult to discuss our data. Moreover, the performances of a plant species in different field experiments will be different, for specific conditions of soil and pollution can significantly affect the metal bioavailability [21].

However, we tried to compare our data with the few results in the literature on phytoremediation experiments in which crops have been studied in field trials. We did not attempt a direct comparison of experimental data obtained from different trials but rather a) An evaluation of the capability of our experimental design compared to others and b) The potential of the phytoremediation technique at the experimental site of Torviscosa.

Keller et al. [22] studied Brassica juncea, Zea mays, Nicotiana tabacum, stands of Salix sp. and Thlaspi caerulescens cultivated over two years in a site polluted by smelter emissions. In other experiments, the accumulation of As and trace metals in Helianthus annuus [22] and in Hordeum distichum, $x$ Triticosecale, Brassica napus and Brassica carinata [23] were studied.

Madejón et al. [24] observed an As extraction of about $3 \mathrm{~g} \cdot \mathrm{ha}^{-1}$ by growing $H$. annuus in a soil polluted by a mine spill. In our case, sorghum removed about 220 $\mathrm{g} \cdot \mathrm{ha}^{-1}$ of As. The removal of Cd calculated by Keller et al. [22] was $6.95 \mathrm{~g} \cdot \mathrm{ha}^{-1}, 41.7 \mathrm{~g} \cdot \mathrm{ha}^{-1}$ and $9 \mathrm{~g} \cdot \mathrm{ha}^{-1}$ for $B$. juncea, $N$. tabacum and $Z$. mays, respectively, while the amount of Cd removed from the soil at Torviscosa was $5.62 \mathrm{~g} \cdot \mathrm{ha}^{-1}$. Lower performances were recorded by Soriano and Fereres [23] in H. distichum (1.41 g.ha $\left.{ }^{-1}\right), x$ Triticosecale $\left(1.95 \mathrm{~g} \cdot \mathrm{ha}^{-1}\right)$, B. napus $\left(2.08 \mathrm{~g} \cdot \mathrm{ha}^{-1}\right)$ and $B$. carinata $\left(2.18 \mathrm{~g} \cdot \mathrm{ha}^{-1}\right)$. 
We have found no data in the literature with which to compare our data for Co removal by crops. We recorded a removal of $\mathrm{Cu}$ within the range $644-820 \mathrm{~g} \cdot \mathrm{ha}^{-1}$, while the values reported by Soriano and Fereres [23] were lower also in this case; H. distichum $57.2 \mathrm{~g} \cdot \mathrm{ha}^{-1}, x$ Triticosecale $51.2 \mathrm{~g} \cdot \mathrm{ha}^{-1}$, B. napus $36.2 \mathrm{~g} \cdot \mathrm{ha}^{-1}$ and B. carinata $37.1 \mathrm{~g} \cdot \mathrm{ha}^{-1}$. The uptake of $\mathrm{Cu}$ calculated by Keller et al. [22] was 146, 474 and $163 \mathrm{~g} \cdot \mathrm{ha}^{-1}$ for B. juncea, N. tabacum and $Z$. mays, respectively.

The removal of $\mathrm{Zn}$ computed from the data collected by Keller et al. [22] was $894 \mathrm{~g} \cdot \mathrm{ha}^{-1}$ for B. juncea, 1,834 $\mathrm{g} \cdot \mathrm{ha}^{-1}$ for $N$. tabacum and $1998 \mathrm{~g} \cdot \mathrm{ha}^{-1}$ for Zea mays. Data for $\mathrm{Zn}$ removal provided by Soriano and Fereres [23] were the following: $1070 \mathrm{~g} \cdot \mathrm{ha}^{-1}$ for $\mathrm{H}$. distichum, 923 $\mathrm{g} \cdot \mathrm{ha}^{-1}$ for $x$ Triticosecale, $902 \mathrm{~g} \cdot \mathrm{ha}^{-1}$ for B. napus and $797 \mathrm{~g} \cdot \mathrm{ha}^{-1}$ for B. carinata. Our sorghum plants showed the same potential. However, in absolute terms, we extracted quite a small amount of elements [9].

More recently, Zhuang et al. [25] provided further information regarding the potential for phytoremediation of sorghum in multi-contaminated soils working with different cultivars of sorghum.

In our experiment, due to the metal-binding capacity of the organic matter, we had expected to observe a lower concentration of metals in the plants grown in the manure amended plots. This occurred for some elements but not for others. The same managing strategy in a polycontaminated soil seemed not to have the expected effects on metal uptake. On the other hand, most metalcontaminated soils contain more than one metal [7]. This aspect poses further technical problems for the agronomical management of phytoremediation projects.

\section{Conclusions}

In the perspective of the extensive application of phytoremediation it is of great importance to understand how the efficiency of the process can be improved through the crop management practices.

In a phytoremediation field trial we tested the effects induced by two different agricultural practices on the process of metal phytoextraction. Some parameters of classical crop growth analysis were used to study the adaptation and the response of plants to the experimental conditions in terms of biomass production and growth rate. This approach can be used profitably in phytoremediation projects to predict the harvest scheduling of the crops.

Under our experimental conditions Sorghum bicolor showed a poor potential for phytoremediation. However, in terms of element removal, it was recorded a positive feedback induced by the agronomic treatments. Since in the experimental design did not consider any practice specifically designed to enhance the bioavailability of the trace metals (e.g. chelating agents), we can assume that sorghum could be potentially more effective than what we observed.

Currently, phytoremediation is not yet a marketavailable green technology. Further investments of intellectual and financial resources will promote a real applicative potential to phytoremediation. More effort should be devoted to develop medium/long term field trials with the twofold objective to test and optimize agricultural practices to make phytoremediation faster and more effective.

\section{Acknowledgements}

This research was part of the project "Phytoextraction of heavy metals in sites polluted by industrial activities: efficiency of soil-plant system", supported by the Italian Ministry of University and Research (N. 2003072589).

\section{REFERENCES}

[1] G. Wu, H. Kang, X. Zhang, H. Shao, L. Chu and C. Ruan, "A Critical Review on the Bio-Removal of Hazardous Heavy Metals from Contaminated Soils: Issues, Progress, Eco-Environmental Concerns and Opportunities," Journal of Hazardous Material, Vol. 174, No. 1-3, 2010, pp. 1-8.

[2] USEPA, "Green Remediation: Incorporating Sustainable Environmental Practices into Remediation of Contaminated Sites," EPA 542-R-08-002, 2008.

[3] ITRC, "Phytotechnology Technical and Regulatory Guidance and Decision Trees," Interstate Technology \& Regulatory Council, Phytotechnologies Team, Washington, D.C., 2009.

[4] J.-P. Schwitzguébel and P. Schröder, "Phytotechnologies to Promote Sustainable Land Use and Improve Food Safety: Outcomes and Outlook from the European COST Action 859," Environmental Science and Pollution Research, Vol. 16, No. 7, 2009, pp. 743-744.

[5] S. P. McGrath and F. J. Zhao "Phytoextraction of Metals and Metalloids from Contaminated Soils," Current Opinion in Biotechnology, Vol. 14, No. 3, 2003, pp. 277-282. doi:10.1016/S0958-1669(03)00060-0

[6] E. Lichtfouse, M. Hamelin, M. Navarrete, P. Debaeke and A. Henri, "Emerging Agroscience," Agronomy for Sustainable Development, Vol. 30, No. 1, 2010, pp. 1-10. doi:10.1051/agro/2009055

[7] N. M. Dickinson, A. J. M. Baker, A. Doronila, S. Laidlaw, and R. D. Reeves, "Phytoremediation of Inorganics: Realism and Synergies," International Journal of Phytoremediation, Vol. 11, No. 2, 2009, pp. 97-114. doi:10.1080/15226510802378368

[8] M. Mench, N. Lepp, V. Bert, J.-P. Schwitzguébel, S. W. Gawronski, P. Schröder and J. Vangronsveld, "Successes and Limitations of Phytotechnologies at Field Scale: Out- 
comes, Assessment and Outlook from COST Action 859," Journal of Soils and Sediments, Vol. 10, No. 6, 2010, pp. 1039-1070. doi:10.1007/s11368-010-0190-x

[9] L. Marchiol, G. Fellet, D. Perosa and G. Zerbi, "Removal of Trace Metals by Sorghum Bicolor and Helianthus annuus in a Site Polluted by Industrial Wastes: A Field Experience," Plant Physiology \& Biochemistry, Vol. 45, No. 3, 2007, pp. 379-387. doi:10.1016/i.plaphy.2007.03.018

[10] R. Hunt, "Plant Growth Curves: The Functional Approach to Plant Growth Analysis," Cambridge University Press, London, 1981.

[11] R. L. Vanderlip, "How a Sorghum Plant Develops," Kansas Agricultural Experiment Station, Manhattan, 1993.

[12] ASTM, "Standard Test method for particle-size analysis of soils," American Society for Testing and Materials, Philadelphia, 1972.

[13] USEPA, "EPA Method 3051: Microwave Assisted Acid Digestion of Sediments, Sludges, Soils and Oils," 3rd Edition, Test Methods for Evaluating Solid Waste, United States Environmental Protection Agency, Washington, D.C., 1995a.

[14] USEPA, "EPA Method 3052: Microwave Assisted Acid Digestion of Siliceous and Organically Based Matrices," 3rd Edition, Test Methods for Evaluating Solid Waste, United States Environmental Protection Agency, Washington, D.C., 1995b.

[15] M. Nadal, M. Schuhmacher and J. L. Domingo, "Metal Pollution of Soils and Vegetation in an Area with Petrochemical Industry," Science of the Total Environment, Vol. 321, No.1-3, 2004, pp. 59-69.

[16] FAO, "Trace Elements in Soils and Agriculture," Food and Agriculture Organization of the United Nations, Rome, 1972.

[17] E. Pilon Smits, "Phytoremediation," Annual Review in Plant Biology, Vol. 56, No. 1, 2005, pp. 15-39.

[18] J. Vangronsveld, R. Herzig, N. Weyens, J. Boulet, K.
Adriaensen, A. Ruttens, T. Thewys, A. Vassilev, E. Meers, E. Nehnevajova, D. van der Lelie and M. Mench, "Phytoremediation of Contaminated Soils and Groundwater: Lessons from the Field," Environmental Earth Sciences, Vol. 16, No. 7, 2009, pp. 765-794.

[19] U. Krämer, "Metal Hyperaccumulation in Plants," Annual Review in Plant Biology, Vol. 61, 2010, pp. 517-534. doi:10.1146/annurev-arplant-042809-112156

[20] R. L. Chaney, J. S. Angle, C. L. Broadhurst, C. A. Peters, R. V. Tappero and D. L. Sparks, "Improved Understanding of Hyperaccumulation Yields Commercial Phytoextraction and Phytomining Technologies," Journal of Environmental Quality, Vol. 36, No. 5, 2007, pp. 1429-1443. doi: $10.2134 /$ jeq2006.0514

[21] D. Hammer and C. Keller, "Phytoextraction of Cd and Zn with Thlaspi Caerulescens in Field Trials," Soil Use and Management, Vol. 19, No. 2, 2003, pp. 144-149. doi:10.1079/SUM2002182

[22] C. Keller, D. Hammer, A. Kayser, W. Richner, M. Brodbeck and M. Sennhauser, "Root Development and Heavy Metal Phytoextraction Efficiency: Comparison of Different Plant Species in the Field," Plant and Soil, Vol. 249, No. 1, 2003, pp. 67-81. doi:10.1023/A:1022590609042

[23] M. A. Soriano and E. Fereres, "Use of Crops for in Situ phytoremediation of Polluted Soils Following a Toxic Flood from a Mine Spill," Plant and Soil, Vol. 256, No. 2, 2003, pp. 253-264. doi:10.1023/A:1026155423727

[24] P. Madejón, J. M. Murillo, T. Maranón, F. Cabrera and M. A. Soriano, "Trace Element and Nutrient in Sunflower Plants Two Years after the Aznalcóllar Mine Spill," Science of the Total Environment, Vol. 307, No. 1-3, 2003, pp. 239-257.

[25] P. Zhuang, W. Shu, Z. Li, B. Liao, J. Li and J. Shao, "Removal of Metals by Sorghum Plants from Contaminated Land,"Journal of Environmental Sciences, Vol. 21, No. 10, 2009, pp. 1432-1437. doi:10.1016/S1001-0742(08)62436-5 